\title{
INFÂNCIA DIASPÓRICA - CAMINHOS (RE)INVENTADOS PELA POESIA BALDIO, DE RUI KNOPFLI E PELO CONTO O BARRIGUDO, DE HÉLDER MUTEIA
}

\author{
Edimilson Moreira Rodrigues \\ Paulo Henrique Carvalho dos Santos
}

Resumo: Objetivamos traçar uma viagem-experiência da infância diaspórica através do conto "O Barrigudo", de Muteia, na companhia da poesia africana de expressão portuguesa, "Baldio", onde o poeta Rui Knopfli, "em seu estado primeiro e embrionário de ser, infantil e poético, mágico e mítico", nos guia sobre o eixo referencial da memória como percurso da história social e literária africana, no tempo-ritmo da infância, qual pátria imaginária. Nesta mobilidade cultural e literária, usamos alguns excertos de Virgílio de Lemos, como líquido revigorante dessa incursão mnemônica e, sempre que possível, em diálogo com outros meninos dos poetas da literatura infantil brasileira. Descobrir o sentido do conto e do poema, proporcionou-nos destruí-los em suas partes avassaladoras, neutralizando sentidos, imagens, metáforas e metonímias, em proveito da excepcionalidade criadora de Knopfli e Muteia que se traduzem nos poetascronista africanos, isto sem olvidar a contribuições de Virgílio de Lemos.

Palavras-chave: Infância. O Barrigudo. Baldio. Diáspora africana.

\begin{abstract}
We aim to trace a journey-experience of diasporic childhood through the short story "O Barrigudo", by Muteia, in the company of African poetry of Portuguese expression, "Baldio", where the poet Rui Knopfli, "in his first and embryonic state of being, childish and poetic, magical and mythical ", guides us on the referential axis of memory as a journey of African social and literary history, in the time-rhythm of childhood, like an imaginary homeland. In this cultural and literary mobility, we use some excerpts from Virgílio de Lemos, as an invigorating liquid from this mnemonic incursion and, whenever possible, in dialogue with other children of Brazilian children's literature poets. Discovering the meaning of the tale and the poem, allowed us to destroy them in their overwhelming parts, neutralizing meanings, images, metaphors and metonymies, in benefit of the creative exceptionality of Knopfli and Muteia that translate into the African poets-chroniclers, without forgetting to contributions by Virgílio de Lemos.
\end{abstract}

Keywords: Childhood. O Barrigudo. Baldio. African diaspora. 
Talvez o segredo daqueles que conseguiram ficar entre as crianças seja o de serem fiéis ao menino que vive dentro deles. De ouvirem a voz de seu próprio inconsciente, e de respeitarem o mistério da infância.

Ana Maria Clara Machado in Resende (1988, p.71)

\section{Introdução}

A literatura africana de expressão portuguesa permite aos seus escritores a possiblidade de voltar ao passado, tanto como forma de denúncia quanto de contemplação daquilo que Ihe fora retirado outrora: a infância, o brincar, o divertir- se; o natural é, agora, dilacerado pelo sistema colonial implantado com dureza nesses países. O debruçarse sobre as memórias do passado pela arte da palavra traz à tona questões históricas e sociais denunciadas por estes autores, que na escrita, despertam o menino escondido dentro deles, testemunha da barbárie colonial.

Objetivamos neste trabalho, analisar a poesia de Rui Knopfli, Baldio, juntamente com o conto de Helder Muteia, "O barrigudo", como produções mnemônicas, reminiscências, viagem ao passado do escritores-meninospoetas, em diálogo com alguns excertos de Virgílio de Lemos, como líquido revigorante dessa incursão mnemônica e, sempre que possível, em diálogo com outros meninos dos poetas da literatura infantil brasileira. 


\section{Meninos da "Morabeza": heróis da decadência}

A infância vivida pelos poetas-cronistas e seus personagens, no desenvolvimento deste trabalho, pode ser considerada como uma literatura infantil diaspórica, por se tratar, tanto no poema "Baldio", de Knopfli, quanto no conto "O Barrigudo", de Muteia, de sentidos de deslocamentos, pois "eleva-se como uma condição determinante na montagem do narrador que - com a competência já demonstrada em outros textos - esses autores constroem, orientados pela perspectivas de balanço da realidade a que nenhum dos dois renuncia" (CHAVES apud SECCO, 2010, p. 15). Isto porque as obras dos autores em análise se configuram como produtos de sentidos diaspóricos infantis. As incursões, nos labirintos do social, traduzem obras da memória dos escritores que viveram os traumas da infância africana e trazem esses traumas como cicatrizes.

Seus personagens realizam a travessia das lembranças e albergam-na no corpo da escrita; são personagens que viveram o que contam, e contam o que viveram como relações possíveis entre cultura e escrita ficcional que se confunde na textualidade literária. Os autores apontam caminhos de comunhão, trazendo suas marcas e suas 
temporalidades históricas para o corpus literário, com teor do infantil. O mnemônico é um escudo à herança cultural que, nos textos, trazem o olhar do colonizador. Este com as armas da destruição; traz o devir de um mundo ainda por construir, esbulhando processos míticos, ideológicos e sociais preexistentes, para imprimir sua representação de violência simbólica e real, no espírito ancestral que fazia do imaginário, socialmente democrático, porque para todos, uma distopia histórica que inverte valores enraizados há séculos: "Meus olhos tremem de dor/ Mas a minha dor maior/ É ser mãe, ser mulher/ Mamanooooo..." (MUTEIA apud RAMOS, 1990, p. 144).

A decadência aqui é entendida como expansão do humor, pois há a "vigilância da consciência individual e uma censura impregnada de todas as leis, tabus e prejuízos impostos por uma civilização complexa, deformando a simplicidade dos sentimentos iniciais, tornam o humor possível" (MOOG, 1964, p. 18). Acrescentamos que o humor, na literatura africana se desdobra em ironia, que questiona o humano diante das imposições do império do capital que tudo menospreza, inclusive as fases de desenvolvimento da infância. No conto "O Barrigudo", de Helder Muteia, temos a "vigilância consciente" do escritor que se molda, 
às metáforas da poesia, para dizer das atrocidades sofridas pelo barrigudo durante um bombardeio aéreo:

De súbito, a terra estremeceu e um barulho estridente espalhou-se, ao mesmo tempo que vários pássaros inundavam os ares velozes, sinistros..., eram 'PÁSSAROS de FERRO'. Faziam avarias, rodopiavam e punham lá em cima os 'OVOS' que, quando chegavam cá em baixo, explodiam... (MUTEIA apud RAMOS, 1990, p. 143)

O teor da decadência infantil se prolonga como "censura impregnada" e se definha quando o narrador declara que "terminava assim, com dez anos apenas, uma existência dura, mas feliz, naquela planície de caniços e mangueiras" (MUTEIA apud RAMOS, 1990, p. 143).

O temporal e o histórico da sociedade africana estão demarcados neste conto que fala da infância de um menino, Bedjú, nas cercanias das cidades "num manto aveludado de caniços e mangueiras" (MUTEIA apud RAMOS, 1990, p. 141). O conto narra a crueldade da vida e da sociedade colonial que menospreza os valores do ser africano, recortado na poética de um menino. O poeta africano funciona assim, como cronista dos fatos sociais que escande o olhar do humano, nas agruras do social, buscando, pelo olhar da infância o tempo das atrocidades. Pois, segundo Novaes, "ser humano é ser temporal. Por isso, a temporalidade é não 
ser só condição da possibilidade da compreensão do ser. Temporalidade significa igualmente o caráter histórico do Dasein, o acontecer de sua existência, embrionário no futuro e passado persistindo ao presente" (NOVAES, 1994, p. 393). Como observamos nesse excerto do conto em análise, no qual os tempos e espaços da poética infantil se fundem:

Só, naquele mundo que já era parte de si mesmo, vieram-lhe, envoltas de cores, as imagens da mãe que devia estar na machamba, e do pai que talvez já tivesse chegado da fábrica. Era feliz, na planície, ninguém o tratava por 'o barrigudo', aliás, todos os meninos ali eram barrigudos. Era apenas o menino da mamana Briana, traquino que nem pai dele quando era dançador de xigubo. (MUTEIA apud RAMOS, 1990, p. 142)

Neste roteiro de travessias da temporalidade, o caráter histórico da opressão fica demarcado no gesto do olhar do narrador para que tenhamos compreensão dos séculos de exploração e escravidão da África. A mãe e o pai trabalham deixando o menino Bedjú só, nas cercanias da casa onde habitavam como seres das fronteiras; habitantes das hecatombes sociais que precisam se distanciar, cada vez mais para longe das cidades. Assim, Muteia, com sua capacidade criativa, aposta no padrão ético da textualidade configurando uma literatura de denúncia das mazelas 
sociais infantis, explorando "a plumagem das palavras com significados" (MACHADO, 2003, p. 15).

A obra $O$ Barrigudo fermenta discussões históricas e sociais, pois mobiliza a possibilidade de sua narrativa capaz de demonstrar espaços e "momentos embrionários" de contextos tão conturbados. Podemos afirmar com Augel que "a simbolização é procedimento estético complexo e multiforme que possibilita afirmar - dentro do espaço da linguagem do colonizador - as especificidades culturais africanas" (AUGEL apud SECCO, 2010, p. 39), como nesta simbolização da morte e sua complexidade em profundo compromisso estético, com a textualidade e elementos da natureza: "ergueu-se novamente, tentou fugir, mas a dor intensa estendeu-o pesadamente por terra ao terceiro passo. Rebolou e quedou-se de barriga para o ar, mirando a silenciosa viagem das nuvens em namoro, sob a capa azul do céu" (MUTEIA apud RAMOS, 1990, p. 143).

Como notamos, são propostas de obras literárias infantis, mas que servem, não somente para serem lidas para crianças, mas para denunciar o mundo que lhes é negado. A criança da diáspora fixa sua imersão neste mundo, quando o autor a apresenta como personagem de uma história social que a alijou inclusive das brincadeiras. 
E estas confirmam o desenho do social que apresenta o homem como herói da decadência quando imita outros pelo que fazem.

Empunhou a fisga de borracha que trazia pendurada no pescoço como se fosse um colar, recolheu algumas das minúsculas esferas de barro que cuidadosamente moldara para servirem de balas, e mergulhou-se no capim. Andou em bicos de pés com mestria implacável, buscou a presa, baixou, fez pontaria e disparou. (MUTEIA apud RAMOS, 1990, p. 143)

A virtuosidade no manejo da narrativa está presente em Muteia. Ele seduz o leitor pelo arranjo das palavras com metáforas inusitadas e insólitas, conduz o leitor para as vielas do texto que o prendem do começo ao fim, qual a presa com a qual se distrai Bedjú. As suas obras são testemunhos da derrocada colonial, com a inserção do ponto de vista do ser criança. A imaginação aqui se irmana às questões sociais reais, os limites entre ficção e invencionice se chocam com a realidade social infantil.

São questões complexas as delimitações de literatura infantil, pois são escritas para crianças por adultos. Aqui a literatura infantil é desdobramento do vivido pelo adulto através dos fatos que conta, como neste texto de Hélder Muteia. São metáforas de um momento histórico que se 
serve da memória do escritor para falar, anos depois, como narrativa de autoafirmação e profundo sentido de liberdade. O autor denuncia a falta de relações sociais que fazem do menino africano objeto de diálogo constante com a flora e fauna como cúmplices das descobertas: "e ele que tanto ansiava ter uma toutinegra, que acompanhasse o cantar do galo, que preenchesse a gaiola deserta e que seria seu maior amigo" (MUTEIA apud RAMOS, 1990, p. 142). Neste excerto anterior está colocada a angústia de Bedjú, pela falta de amigos, mas acima de tudo, há o poder da palavra do poeta da infância que cria

- poder de resistência dessa coisa, aparentemente tão frágil e precária, que é a palavra, (literária ou não) prova de maneira irrefutável que a comunicação entre homens é essencial à sua própria natureza", pois como aduz a autora, "O impulso de contar estórias deve ter nascido no homem no momento em que ele sentiu necessidade de comunicar aos outros certa experiência sua, que poderia ter significação para todos". (NOVAES, 1991, p. 13)

A literatura africana adulta ou infantil, está marcada por crianças que se assemelham a heróis da decadência. Os poetas da infância mnemônica encaram fatos que guardam estilos de pureza submissas aos recortes de memórias e atacam sem tréguas, ainda que subliminarmente, os 
padrões estabelecidos pelo colonialismo. Contrariando o final feliz dos contos de fadas, eles, os poetas, vão enfatizar, "com ligeiras diferenças, mas sempre insistindo no enfoque da vida cotidiana, familiar, onde os problemas de desajuste individual ou social serão resolvidos por um comportamento ético-afetivo ideal" (COELHO, 1991, p. 191). Deste modo, a finalização do conto "O Barrigudo" apresenta esta assertiva de Nelly Novaes Coelho, porque o narrador, imantado no eu-poético autoral, dá outro tom ao final do conto.

Há sentimentos que não se escondem, nem pintados com a cor negra do luto que usamos. Há factos que transbordam das capacidades de uma mãe que nada tem a haver (sic) com o napalm, nem com quem a inventou; factos que tão pouco podem ser resumidos numa estória como esta. Naquela noite os batuques não soaram. (MUTEIA apud RAMOS, 1990, p. 144)

O poeta em análise é dono de um estilo atraente e de uma imaginação extraordinária. Usa a potência da linguagem como potência da poesia. Ela tudo permite no corpo da palavra, com sua possibilidade de tocar verdades evidentes, levanta hipóteses e traz dúvidas. O mundo da poesia denuncia "sentimentos que não se escondem" e, ainda, "factos que transbordam das capacidades" 
conservadas na memória dos que viveram o colonialismo, as lutas pela independência e os problemas internos.

As obras, dos poetas elencados, surgem do reinventar missosos, como magia das palavras que vertem no oral e na memória, porque é "onde as guerras não conseguiram destruir totalmente a magia verbal própria da ancestral palavra africana" (SECCO, 2007, p. 11), como "factos que tão pouco podem ser resumidos numa estória como esta" (MUTEIA apud RAMOS, 1990, p. 143).

Os textos aqui reunidos - "Baldio", de Knopfli e "O Barrigudo", de Hélder Muteia - são obras da imaginação criadora, mas que dialogam com criatividade imagética do real. Isto porque "a literatura de imaginação ou de criação é a interpretação da vida por um artista através da palavra" (COUTINHO, 2008, p. 49).

\section{A sedução do potencial lúdico - "Baldio"}

A pesquisa ${ }^{1}$, pelos fragmentos poéticos, revela-nos algo instituidor para o poeta-militante deste período e, indubitavelmente, ao longo de anos anteriores: a poesia

1 Os textos aqui selecionados são, portanto, espelho e reflexo desse homem à busca de sua identidade conquistada a ferro e palavra que cimentam Direito e Liberdades em Moçambique, no período de 60 e 80 do Século XX. E a poesia Baldio do poeta Rui Knopfli, nos servirá para analisar a condição infantil neste período, isto, claro, de mãos dadas ao poeta Virgílio de Lemos. É inegável que a literatura africana de expressão portuguesa, produzida no século XVIII, até o final do século XIX, é uma obra de testemunho social da realidade africana que tem na língua portuguesa seu aporte de expressivo significado com marcas da verve infantil que nele resta como signo de memória (RODRIGUES, 2020). 
serviu como guarnição e foi guarnecida pelo impulso básico do ser africano ao revelar seu processo histórico e social, que, como aduz Coelho,

no processo histórico que the cabe viver o homem está sempre impulsionado em três direções básicas: a que o leva à sua realização interior, como ser individual; a que o leva a integrar-se no meio que o cerca, como ser social; e a que o faz encarar e perscrutar o Absoluto (Deus, Eternidade, Mistério da Condição Humana), como ser eterno que ele se pressente, devido ao espírito ou elã vital que o anima. (COELHO, 1986, p. 108)

A poética africana é testemunha partícipe - dificilmente apreensível no nível de produção e recepção estética elementar e ocidental - desta busca de realização como ser individual que o direciona ao âmago do social. O espírito que a anima é a história cultural do seu povo, que a faz encarar e perscrutar, não somente o absoluto, mas o inadmissível alavancado pela máquina colonial. E, há muito, adormecida na engrenagem da fábrica de imagens infantis - a poesia, que em muito constrói a identidade do homem, em harmonia com sua forma discursiva que o insere nos grandes temas diaspóricos, identitários e sociais, através da língua ${ }^{2}$ do dominante.

2 Língua portuguesa que é recriada num "corpo a corpo", "de sopro em sopro", de corpo de grito em corpo de silêncio. Silêncio em silêncio... Língua capaz de ser "movimento", "vertigem" que eroticamente, não esconde as chagas da memória e da própria história. E da história de cada um dos povos e civilizações que participaram na expansão marítima, no tráfego de escravos, no escravismo... O poeta viaja pelo corpo. E pelo corpo da memória (AMÉRICO NUNES apud DE LEMOS, 1999, p. 08). 
Como ilustra Xavier, “a arte, e em especial a literatura, contribui significativamente para essa apropriação da Língua Portuguesa desprovida de conotações imediatas a nível histórico-colonialista, servindo para a afirmação de uma identidade nacional" (XAVIER, 2017, p. 35), que se expande, acrescentamos, como códigos e símbolos de identidade partilhada, onisciente e consentida.

“A História que há-de ler-se é por mim escrita. / Anonimato igual nos cobrirá. A estas palavras não" (RUI KNOPFLI, 1983, p. 362). Coube, deste modo, ao escritor africano, a tarefa de escrever a sua história e nela moldar, ou melhor, forjar sua identidade com palavras fragmentadas em sílabas - a céu aberto - descobertas no fogaréu da sociedade.

Identidade esculpida em palavras e por um "servidor incorruptível da verdade e da memória": o poeta (KNOPFLI, 1983, p. 361). Aquele que faz do arcabouço poético suas incursões, no amago da verdade. Ele é historiador estético dos fatos sociais e a "Literatura, justamente a Literatura! - herda as pesadas tarefas éticas, ideológicas e mesmo políticas que tinham sido uma vez confiadas a discursos mais técnicos ou práticos" (EAGLETON, 2011, p. 61-62). Esta é, portanto, uma via de mão dupla. O escritor se faz poeta para escrever a história social do homem, mas também a de sua 
nação, e indubitavelmente, a dele enquanto escritor cônscio de sua atuação.

O poeta se converte em historiador e a literatura em estratos da faculdade histórica. Não é que o poeta e a história trabalhem com instrumentos diversos; mas com o mesmo instrumento - a palavra - de modo diferente. Eis a delação do poeta que ressoa nas linhas do verso: "Tenho meu pequeno tratado de sociologia, / uma sociologia de horizontes modestos. / Ponho-me a remorder / continentes, povos, hábitos e costumes (KNOPFLI, 1983, p. 72).

Identidade e memória, no texto literário africano, se mostram em entrelaçamento recíproco. Ambos atravessam a significação de ser do homem africano como processo vivencial constitutivo de sua expressão. Lembrar e identificar-se com e no texto - uma das mais nobres manifestações culturais africana -, são seduções constitutivas do potencial de escrita, enquanto aquisição de saberes que se adquirem no ato da criação.

A sedução deste potencial está neste texto que nos convida a incursionar numa viagem ${ }^{3}$ nos escombros da sociedade africana de parte do século XIX e XX. O poema

3 A viagem através do discurso e discursos, que antecedem todo acto de criação poética, é sempre o início da grande aventura na floresta da significação. Rui Knopfli mostra, desde a primeira hora, uma notável segurança no comando das imagens e das associações que elas evocam, imprimindo-lhes o cunho inconfundível da sua própria angústia (REBELO apud KNOPFLI, 1982, p. 11). 
nos apresenta uma visão, ainda que muito fragmentada, da infância, mas que revela dados substanciais à análise literária. Como nos orienta Nelly Novaes Coelho (1974), podemos afirmar que,

a análise de texto atomiza o texto poético, fragmenta-o em seus vários elementos constitutivos. Destrói de início a beleza e emoção do poema, para que, numa síntese final, com suas partes outa vez reintegradas no todo, o poema surja aos nossos olhos muito mais rico em suas significações e muito mais belo em sua dimensão criadora. (COELHO, 1974, p. 51)

Deste modo, destruiremos o poema Baldio em suas partes avassaladoras, neutralizando sentidos, imagens, metáforas e metonímias, em proveito da excepcionalidade criadora de Knopfli, que se traduz no poeta africano de recorrência telúrica e infantil, isto sem olvidar as contribuições de Virgílio de Lemos. Temos aí, o acréscimo lúdico, de sua existência de poeta, o qual se amplia na contribuição aos estudos da literatura infantil africana, que se ampara no texto poético adulto, em consórcio com as ideias de Bartolomeu Campos de Queirós: "há que se afinar o corpo até o último sempre / exercer-se como instrumento capaz de receber a poesia do mundo" africano, neste potencial lúdico: 


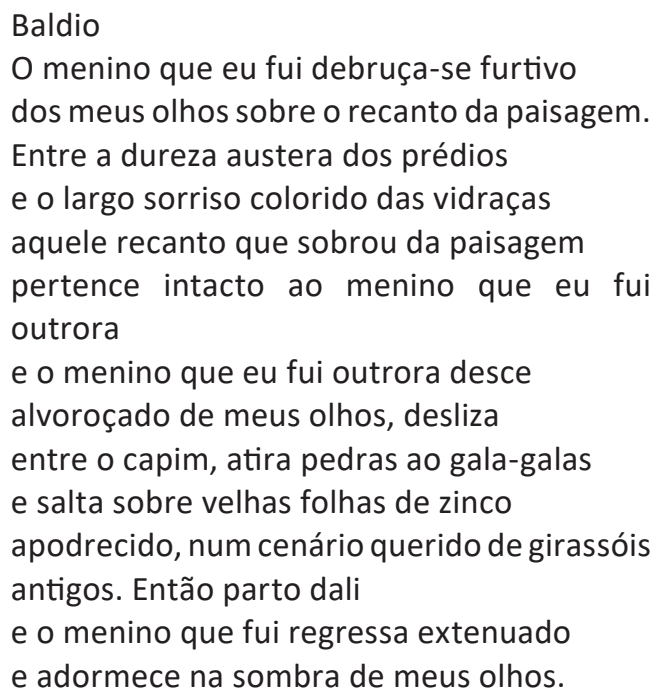

Após a fragmentação dos seus vários elementos constitutivos, no amplo campo da exegese poética, rumo à síntese final, desta vez, à luz dos saberes da infância, "muito mais belo em sua dimensão criadora", vamos "incorporá-lo, também, à necessária pluralidade da leitura, na certeza de que é impossível pretender fixar um sentido único que encerre em um esquema estático e rígido toda a densa flutuação semântica" (MACHADO, 2003, p. 101), do texto de Knopfli.

\section{O poeta, artífice da infância}

Usando como nossas as palavras de Vânia Resende (1988), dizemos que a análise que se desenvolverá sobre o menino 
na literatura africana, mais especificamente na poesia de Moçambique, tendo o poeta como artífice da infância, "busca esclarecer o sentido que cada artista, particularmente, dá à infância, quando a traz à tona ao campo da literatura" (RESENDE, 1988, p. 23). Pois, o modo como o artista da palavra evoca a infância nos seus textos "leva-nos a constatar, na maneira deles, significados humanos e estéticos profundos, emergentes de um mundo metafórico, em que se cruzam símbolos da imaginação criadora e imagens da realidade infantil" (RESENDE, 1988, p. 23).

Os símbolos que cruzam infância e literatura, decalcam violências da "magoada realidade de um céu / ardendo em feridas" (KNOPFLI, 1983, p. 110); o céu é o africano, e a realidade infantil é aquele da "noite grávida de punhais", quando se apossou da terra africana: o colonialismo. A realidade infantil, pensando ainda com Vânia Resende, é "fonte mágica, vivificante, de que o criador pode tirar grandes efeitos, realizando, de forma plena, a ficção da sua escritura" (RESENDE, 1988, p. 23).

E o denunciador desta "fonte mágica" é, para este primeiro momento, o escritor africano Rui Manuel Correia Knopfli, que nasceu em Inhambane, em 1932, e faleceu em Lisboa, em 1997. Como aduz Saúte, 
para além de ter sido um dos primeiros contistas moçambicanos, foi também um pioneiro do ensaísmo crítico. A sua poesia constitui um dos edifícios fundadores da moçambicanidade moderna, devendose-lhe, em grande medida, o facto de Moçambique possuir uma tradição eclética e cosmopolita. (2004, p. 249)

E para Knopfli, a ficção da sua escritura é o texto poético "Baldio", do qual vamos tentar analisar os "grandes efeitos" provocados nestes receptores, da arte poética, que somos nós, através dos "símbolos da imaginação criadora": a palavra poética. Porque como diz Nietzsche em O Nascimento da Tragédia, fragmento 44: “[...] é a arte o único modo que sobrou de existência, devido a que não pode ser dissolvida pela lógica" (NIETZSCHE apud DE MAN, 1977, p. 125) e, no caso da escritura africana, não pode ser dissolvida pela lógica do dominante.

Isto porque a literatura africana é fruto da manifestação coletiva do pensador africano que se impõe, através da palavra, como arma, aos ditames do colonizador. "A imposição dos modelos do colonizador não ocorre, isso é patente, sem a resistência do colonizado" (SOUZA e SILVA, 1996, p. 14). Desta forma, o rompimento de paradigmas está pontuado no material produzido, decalcando símbolos de resistências, imprimindo respostas com doses de 
desconfianças, produzindo imitações, através do uso do idioma, com pitadas de amarguras no cardápio da ironia, alijando os traços artificiais do colonizador para impor os traços culturais autênticos do colonizado.

No amplo espectro de criação poética, o texto, artefato da memória do poeta, torna-se móvel, instável, tangenciando os espaços de representação que se incorporam em memória coletiva escrita ${ }^{4}$ da sociedade africana, com todos os percalços sociais para fazê-la - a criação poética - emergir do anonimato. A produção artística da África tem uma preocupação central na desconstrução da visão eurocêntrica da arte, evidenciando os saberes étnicos enquanto diversidade que os constitui.

E os escritores, também, artífices da infância, nos proporcionam um passeio pelos territórios da infância; são eles próprios os personagens, numa exposição dura e crua da realidade vivida. Contam para não esquecer e lembram para contar o que Ihes foi impossibilitado de

4 Diferentemente da memória coletiva oral, pois segundo Furé (1977), "entre muchos pueblos sudaneses, este papel de memoria colectiva es desempeñado por los griot, casta de narradores profesionales. El griot es el príncipe de los poetas africanos. Durante cinco años vive separado del resto de la comunidad, aprendiendo en su retiro el arte de su profesión. Al cabo de ese tiempo, durante el cual los maestros griot le han revelado los secretos del arte poético, de la danza, de la pantomima, del cuento, vuelve a integrarse a la vida social. El griot es poderoso, pero también despreciado. Al ser hombre de casta, no puede casarse con los nobles ni las gentes del común; tampoco participar en ciertas cofradías de iniciación. Hasta posee vestuario especial. Sin embargo, se le teme, por su lengua hábil, por saber tejer el comentario sarcástico en medio del canto, por ser el maestro de la sátira. Todo lo que diga el grit se sabrá en el pueblo, se trasmitirá boca en boca. La persona que sea objeto de su burla se convertirá en el hazmerreír del grupo" (FURÉ, 1977, p. 13, Tomo I). 
viver: a infância e suas formulações que surgem, hoje, como desenhos imantados no desejo do adulto, prenhe de vida que se alberga na criança de outrora.

Isto para confirmar que o menino, o ser criança, pela não vivência plena em seu tempo, pelo dilaceramento do colono, revive na derme do homem-poeta. E ele, acorda-o, para vivenciar um tempo que foi tangido pela violência, mas que aproveita o mínimo que resta nos porões da memória para narrar seu momento idílico: "O menino que eu fui debruçase furtivo / dos meus olhos sobre o recanto da paisagem".

Importa destacar aqui, que o menino surge do olhar do poeta Knopfli, como memória imagética, um quadro suspenso, uma imagem que retorna pelo poder sugestivo da palavra, em segurança; pois, "o único abrigo disponível para o intelectual é o lugar frágil e vulnerável da escrita, onde ele reinventa sua memória e sua identidade" (PEREIRA apud SOUZA, 2009, p. 80). É assim também para o infantil: olvidado, temporalmente, pelo ser adulto, fala uma verdade furtiva, como se o ser pueril, ainda tivesse certo receio de vir, inteiro, à tona; como faz o escritor moçambicano neste texto.

O poeta - ao descrever o menino - reinventa sua história, no manto vulnerável da escrita furtiva, que o traz imantado 
em outro ente, a natureza, também fragmentada - "o recanto da paisagem". No entanto, ela o ajuda a reconstruir sua identidade, não mais na periferia da linguagem, mas no centro dela, mesmo ciente de que: "o passado nunca volta senão como contraponto à aceleração do tempo presente" (SOUZA, 2009, p. 104-105).

Por isso, o poeta, como um filósofo, puxa da cartola aquele passado armazenado no texto/memória da infância, numa hermenêutica consagrada ao presente: "o menino que eu fui outrora desce/ alvoroçado de meus olhos". Ele desce, está no tempo presente, indicando o modo da certeza gramatical, mas também da fidúcia do retorno, que tenta recompor o eixo estrutural do ser adulto, no ser criança, do passado.

Deste modo, escrevendo sobre a experiência da infância, Knopfli também escreve sobre a diáspora africana. Ele dispersa, semeia a identidade forjada pelos recantos do seu vasto continente, porém, sempre "Ilha de Moçambique" (KNOPFLI, 1982, p. 75) e sempre o mesmo desejo dos poetas "de voltar às praias / da infância" (ARMANDO ARTUR apud SAÚTE, 2004, p. 555).

Ao nomear o menino embaixador de suas emoções, no texto "Baldio", o poeta se exila no tempo da infância, para aludir, com a criatividade, seus saberes multiculturais, sem 
esquecer a natureza, cúmplice e ornamento da imagem poética - sugestiva de um tempo sem retorno, disperso na metáfora ${ }^{5}$, a qual, ela mesma, nos indica a dispersão por todos os campos do social, mas também da poesia "no futuro os olhos das crianças" (MANUEL RUI apud SECCO, 1996, p. 57), somente porque, “a dialética que pulsa na vida da poesia não é diferente da dialética social" (BOSI, 1977, p. 61).

\section{Considerações finais}

Não basta que a situação de colono e dominado esteja anunciada nesse ou aquele poema, é necessário que se descole da poesia de combate, como poesia de denúncia das atrocidades políticas e sociais acometidas aos seres, também, de tenra idade. Tais poemas devem ser inseridos na "poética da negritude infantil". De todo modo, a percepção de ser infantil, a infância efetiva e verdadeira, deve ser coletada da poética daquele momento histórico como delação dos poetas, "os únicos companheiros da

5 O conceito de metáfora, neste momento, é pensado como discutido nas Ciências Sociais contemporâneas por agregar os aspectos de mobilidade e de insubmissão inerentes a essa figura retórica. O termo metáfora deriva do grego metaphorá que, por sua vez, é a junção dos elementos meta (sobre, entre) e pherein (transporte, mudança). Assim, pode-se notar, já a partir de sua etimologia, a ideia do transportar algo de um lugar ao outro, no caso, transportar o sentido próprio de uma palavra para o sentido figurado. Isso fica claro a partir das palavras de Aristóteles (384 a.C. - 322 a.C.), um dos primeiros teóricos a tratar do assunto: "a metáfora consiste no transportar para uma coisa o nome de outra, ou do gênero para a espécie, ou da espécie para o gênero, ou da espécie de uma para a espécie de outra, ou por analogia" (POLONI; BERND, 2010, p. 269). 
infância / foram meninos negros de olhos tristes" (DE LEMOS apud SAÚTE, 2004, p. 209); mas também daquele "servidor incorruptível da verdade e da memória / (que escreve) palavras terríveis / de ignomínia e acusação" (KNOPFLI, 1983, p. 361), com a mesma estratégia de análise que nos ensina Costa Andrade: "leio em teus olhos / a minha infância / como quem olha um retrato/ envelhecido e mudo..." (COSTA ANDRADE apud SECCO, 1996, p. 51).

Do conto "O Barrigudo" pudemos descobrir os "caminhos inventados" pelo Barrigudo, que se absorve como todo menino no chamado redentor da mãe: "O maior prazer sentia-o quando, embrenhado nas suas correrias normais por entre os carreiros, ouvia a mãe chamá-lo, num grito que transbordava por toda a planície: 'Bedjuooouuu!'” (MUTEIA apud RAMOS, 1990, p. 142). O conto nos provocou definir parte deste trabalho de infância diaspórica, bem como nominalizar o artigo, visto que os caminhos não percorridos pelo futuro adulto, impossibilitados pela atrocidade das bombas, trouxe-nos a imagem de caminhos (re)inventados pelos poetas.

Descobrir o sentido do conto e do poema, proporcionounos destruí-los em suas partes avassaladoras, neutralizando sentidos, imagens, metáforas e metonímias, em proveito 
da excepcionalidade criadora de Knopfli e Muteia que se traduzem nos poetas-cronista africanos, isto sem olvidar as contribuições de Virgílio de Lemos.

\section{Referências}

BANDEIRA, Manuel. Estrela da vida inteira. Rio de Janeiro: Nova Fronteira, 1993.

BERND, Zilá. Dicionário das mobilidades culturais: percursos americanos. Porto Alegre: Literalis, 2010.

BOSI, Alfredo. O ser e o tempo da poesia. São Paulo: Cultriz, 1977.

CALDERÓN, Demetrio Estébanez. Breve diccionario de términos literarios. Madri: Alianza Editorial, 2015.

COELHO, Nelly Novaes. Panorama histórico da literatura infantil-juvenil. Rio de Janeiro: Ática, 1991.

COUTINHO, Afrânio. Notas de teoria literária. Petrópolis/Rio de Janeiro: Editora Vozes, 2008.

DE MAN, Paul de. Alegorías de la lectura. Lenguaje figurado en Rousseau, Nietzsche, Rilke e Proust. Barcelona: Lumen, 1977.

EAGLETON, Terry. A ideia de cultura. São Paulo: Editora Unesp, 2011.

EAGLETON, Terry. Marxismo e crítica literária. São Paulo: Editora Unesp, 2011.

FANON, Frantz. Pele negra. Máscaras brancas. Salvador: EDUFBA, 2008. FIGUEIREDO, Eurídice. Conceitos de literatura e cultura. Rio de Janeiro: UFJF/EDUFF, 2012.

FURÉ, Rogelio Martínez. Poesía anónima africana. Tomo I. Habana: Lira, 1977.

GADAMER, Hans-Georg. Hermenêutica da obra de arte. São Paulo: Marins Fontes, 2010.

GOMES, Renato Cordeiro. Todas as cidades, a Cidade. Rio de Janeiro: Rocco, 1994. 
HALL, Stuart. Da diáspora: identidades e mediações culturais. Belo Horizonte: Humanitas/UFMG, 2008.

KNOPFLI, Rui. Memória consentida: 20 anos de poesia (1959/1979). Lisboa: Casa da Moeda, 1982.

LEMOS, Virgílio de. Ilha de Moçambique - a língua é o exílio do que sonhas. Maputo: AMOLP, 1999.

MACHADO, Ana Maria. Recado do nome: leitura de Guimaraes Rosa à luz dos nomes de seus personagens. Rio de Janeiro: Nova Fronteira, 2003. MACHADO, Nauro. Antologia poética. Brasília/São Paulo: Quírion/INL/MEC, 1980.

MERLEAU-PONTY, Maurice. O visível e o invisível. São Paulo: Perspectiva, 2005.

MOOG, Viana. Heróis da decadência: Petrônio, Cervantes, Machado de Assis. Rio de Janeiro: Civilização brasileira, 1962.

NOVAES, Adauto. Artepensamento. São Paulo: Cia das Letras, 1994.

RAMOS, Ricardo. Contos moçambicanos. São Paulo: Global Editora, 1990.

RESENDE, Vânia Maria. O menino na literatura brasileira. São Paulo: Perspectiva, 1988.

SAÚTE, Nelson. Nunca mais é sábado: Antologia de poesia moçambicana. Lisboa: Dom Quixote, 2004.

SECCO, Carmen Lucia Tindó. Ensaios sobre literatura infantil de Angola e Moçambique: Entre fábulas e alegorias. Rio de Janeiro: Quartet: UFRJ Centro de Letras e artes, 2007.

SECCO, Carmen Lucia Tindó. África, escritas literárias: Angola, Cabo Verde, Guiné-Bissau, Moçambique, São tomé e Príncipe. Rio de Janeiro: Editora UFRJ/Angola: UEA, 2010.

SOUSA e SILVA, Manoel de. Do alheio ao próprio: a poesia em Moçambique. São Paulo: Edusp/Editora UFG, 1996.

SOUZA, Eneida Maria de. Modernidades alternativas na América Latina. Belo Horizonte: Humanitas/UFMG, 2009. 
TASENDE, Ana Maria Platas. Diccionario de términos literarios. Madrid: Espasa, 2000.

XAVIER, Lola Geraldes. Literaturas africanas em português: uma introdução. Macau: Instituto politécnico de Macau, 2017.

\section{Edimilson Moreira Rodrigues}

Doutor em Estudos da Literatura, pela Universidade Federal do Fluminense (UFF)

Professor do Curso Interdisciplinar de Licenciatura em Linguagens e Códigos- Língua Portuguesa, da Universidade Federal do MaranhãoUFMA Campus São Bernardo.

Líder do Grupo de Estudos de Tradução e Intermidalidade em Língua Espanhola - AXOLOTL.

E-mail: em.rodrigues@ufma.br

Lattes: https://lattes.cnpq.br/7625644497330954

ORCID iD: http://orcid.org/0000-0003-1404-4381

\section{Paulo Henrique Carvalho dos Santos}

Graduado em Licenciatura em Linguagens e Códigos- Língua Portuguesa, pela Universidade Federal do Maranhão- UFMA Campus São Bernardo. Membro do Grupo de Estudo e Pesquisa sobre Formação e Prática Docente de Línguas, Práticas de Linguagem e Memórias do Ensino de Espanhol no Maranhão (GEPFMEM), com pesquisa na Linha 3: Memórias do ensino de espanhol no Maranhão.

E-mail:pauloh.16@hotmail.com

Lattes: https://lattes.cnpq.br/9327066479116564

ORCID iD: http://orcid.org/0000-0002-4125-0888 